\title{
COMPETÊNCIAS TRANSVERSAIS EM ORGANIZAÇÕES DE ENSINO SUPERIOR ${ }^{1}$
}

\author{
TRANSVERSAL COMPETENCES IN HIGHER EDUCATION ORGANIZATION
}

\author{
Carina Rejane Pavão Garcia² ${ }^{2}$ Janaina Marchi $^{3}$ e Lucas Almeida dos Santos ${ }^{4}$
}

\section{RESUMO}

O presente estudo da área de Gestão de Pessoas foca nas competências transversais observadas no contexto do trabalho em organizações de ensino superior. Com isso, entende-se que as profissões têm um grande valor social, variando suas formas de atuação e a natureza qualitativa dos serviços perante as necessidades humanas. Assim, é imprescindível, em toda e qualquer profissão, refletir acerca das habilidades pessoais e interpessoais de trabalhadores inseridos em organizações de ensino superior. O objetivo nesta pesquisa é compreender, por meio da literatura da área de Gestão de Pessoas a abordagem entre as competências transversais de trabalhadores em organizações de ensino superior. Para tanto, o referido estudo tem enfoque qualitativo, bibliográfico e de caráter explicativo. Como principais resultados encontrados, percebeu-se que, no contexto geral apresentado nos resumos, sobretudo, a nível de metodologia, resultados e conclusão, os textos apresentaram suas análises focando em competências no âmbito discente nas organizações superiores. Tal movimento, aborda como principal foco a formação profissional voltadas ao desenvolvimento de competências transversais. Não se encontrou, por sua vez, trabalhos que abordassem a importância do desenvolvimento destas competências a nível técnico - administrativo e demais trabalhadores nestas organizações, o que demonstra uma lacuna a ser explorada na área.

Palavras-chave: Capacidades; Gestão De Pessoas; Instituições; Educação.

\section{ABSTRACT}

This study in the area of People Management focuses on transversal competences observed in the context of work in higher education organizations. Thus, it is realized that professions have a great social value, varying their ways of acting and the qualitative nature of the services necessary for human needs. Therefore, it is essential, in any and every profession, to reflect on the personal and interpersonal competence of workers inserted in higher education organization. The objective of this research is to understand, through the People Management literature, an approach between the transversal competences of workers in higher education organization. For this purpose, this study has a qualitative, bibliographic and explanatory focus. As main results found, it was observed that in the general context presented in the abstracts, above all, at the level of methodology, results and conclusion, the texts sources their analyzes focusing on competences in the scope of students in higher associations. Such movement addresses as its focus on the professional training aimed at the development of transversal competences. In turn, no works were found that addressed the importance of developing these skills at the administrative technician level and other qualified workers, which demonstrates a gap to be explored in the area.

Keywords: Capacities; People Management; Institutions; Education.

1 Artigo resultante do trabalho final de graduação.

2 Aluna egressa do Curso Tecnólogo em Gestão de Recursos Humanos. E-mail: gabi.depra90@gmail.com

3 Professora Mestra em Administração da Universidade Franciscana. E-mail: janaina.marchi@ufn.edu.br

4 Professor Doutor em Administração da Universidade Franciscana. E-mail: lucas.almeida@ufn.edu.br 


\section{INTRODUÇÃO}

O presente estudo voltado para a área de Gestão de Pessoas, tem como temática de pesquisa as habilidades comportamentais observadas no contexto do trabalho em organizações de ensino superior. Nesse contexto, no atual mundo globalizado as profissões têm um grande valor social, variando suas formas de atuação e a natureza qualitativa dos serviços perante as necessidades humanas. Sobe este viés, é imprescindível, em toda e qualquer profissão, refletir acerca das habilidades pessoais e interpessoais de trabalhadores inseridos em organizações de ensino superior. Segundo Moscovici (2007, p. 36), "competência interpessoal é a habilidade de lidar eficazmente com relações interpessoais, de lidar com outras pessoas de forma adequada às necessidades de cada uma e às exigências da situação”. Em outras palavras, eficazmente pode-se argumentar que a maneira pela qual os profissionais de qualquer área fazem perguntas aos seus clientes ou colaboradores tendo ou não estabelecido um clima psicológico favorável e uma relação de confiança, pode influenciar as informações que recebe.

Hodiernamente, para Martins (2017), o conhecimento humano avilta exponencialmente e dessa forma, a capacidade de aprender, criticar, desenvolver novos conhecimentos e de compartilhar o que se sabe com outras pessoas é relevante. Nessa esteira de pensamento, o sucesso profissional se dá por meio do desenvolvimento das habilidades de adquirir novos conhecimentos, consolidar esses conhecimentos adquiridos e de compartilhar esses conhecimentos com outras pessoas. Numa perspectiva organizacional, percebe-se que as organizações estão contratando colaboradores adeptos de conhecimentos, de capacidade técnica, as hard skills, mas os promovem e os demitem com base em suas habilidades de soft skills. Para o autor supracitado (2017, p. 8), esse define hard skills e soft skills da seguinte forma: os hard skills são as competências técnicas ensinadas na escola e podem ser adquiridas por meio de treinamento e estudo. Os soft skills, por sua vez, são algumas atitudes e habilidades comportamentais inatas ou aperfeiçoadas por cada pessoa, e não ensinadas nas escolas.

Nas instituições de ensino superior, assim como em outras organizações, o desenvolvimento de competências no seu corpo de colaboradores deve ser constante. Nessa esteira de pensamento, Fleury e Fleury (2010) apontam que a formação de competências está relacionada também à definição da estratégia organizacional, portanto só ocorre o desenvolvimento de um em relação ao outro. A eficiência da organização em atingir resultados está ligada ao desenvolvimento de competências na gestão de recursos humano e sua interligação com a estratégia organizacional.

Em outros termos, as habilidades técnicas são conhecimentos científicos adquiridos na universidade e os soft skills são caracterizados pelo caráter de cada ser humano aperfeiçoado por cada pessoa mediante valores, princípios e crenças. Nesse sentido, as empresas optam por colaboradores com habilidade de aprender rápido e de se expressar melhor, para, assim, compartilhar seus planos com colegas de trabalho e clientes (FLEURY; FLEURY, 2010). Logo, compreende-se a importância para as instituições de ensino superior, que os colaboradores tenham habilidades skills, pois essas são 
relevantes para o desenvolvimento pessoal e intelectual dos colaboradores e também da organização. Desse modo, o objetivo da pesquisa é compreender, por meio da literatura da área de Gestão de Pessoas a abordagem entre as competências transversais de trabalhadores em organizações de ensino superior.

Ainda, compreende-se que esta pesquisa seja relevante quanto ao entendimento do universo acadêmico das Instituições de Ensino Superior e o quanto essas necessitam desenvolver competências em seus colaboradores, para que possam qualificar ainda mais os serviços prestados, bem como promover mudanças importantes que influenciam o comportamento individual e comportamental desses.

\section{REFERENCIAL TEÓRICO}

Neste capítulo, são abordados de forma fundamentada, os principais conceitos teóricos referentes a esta pesquisa, a saber: competências e habilidades: diferenciação dos termos; competências transversais no ambiente das organizações.

\section{COMPETÊNCIAS E HABILIDADES: DIFERENCIAÇÃO DOS TERMOS}

Neste capítulo, aborda-se o que os textos: Mapeamento das competências transversais: autopercepção dos alunos de Gestão Empresarial em uma Instituição de Ensino Superior Tecnológica; Autopercepção de competências transversais de trabalho em universitários: construção de um instrumento; Competências transversais e Desempenho empresarial: uma análise conceitual comparativa apresentam como definições de competências e de habilidades. Assim, faz-se importante destacar que a pesquisa em si no âmbito da educação profissional não basear-se-á apenas em transmitir conhecimento teórico ou técnico, mas sim estudar competências genéricas, relacionadas ao mundo do trabalho, assim, denominadas competências transversais (hard skills e soft skills).

Na concepção de Garcia et al. (2017), sobre competência, referem que a noção de competência vem se transformando ao longo do tempo, permitindo encontrar diferentes interpretações para o mesmo termo. Por esse motivo, definir o conceito de competência é uma tarefa complexa, porém de suma importância, dada a sua relevância em diversos contextos da vida real.

Em outras palavras, o termo competência tem relevância em diversos contextos da vida real, uma vez que competências humanas podem ser vistas como combinações sinérgicas de conhecimentos, habilidades e atitudes, expressas pelo desempenho profissional dentro de determinado contexto organizacional, que agregam valor a pessoas e organizações. Nesse sentido, as referidas autoras informam no artigo que apesar de várias abordagens diferentes com relação ao conceito, pode-se dizer que a ideia de competência se refere à aprendizagem e ao desenvolvimento adquirido na realização adequada e observável de um determinado tipo de atividade ou tarefa (GARCIA, et al., 2017). 
Somando à isso, Silva et al. (2012) enfatizam que a competência técnica é apoiada na maioria das vezes, em outras competências, mais genéricas, relacionadas ao mundo do trabalho. Desse modo, tais competências denominadas transversais entendidas como atitudes, capacidades e habilidades contribuem para a atuação de todo e qualquer indivíduo em diferentes situações no ambiente de trabalho e podem ser transferíveis de um contexto para o outro ao longo da vida.

Moura et al. (2015) destacam que as competências transversais são descritas usando termos associados com traços de personalidade como otimismo, responsabilidade, senso de humor, integridade e habilidades que podem ser praticadas no dia a dia, ou seja, como a empatia, o trabalho em equipe, a comunicação, a negociação, o equilíbrio emocional e a capacidade de ensinar. Nesse sentido, Garcia et al. (2017), Moura et al. (2015) e Silva et al. (2012), ao abordarem em suas pesquisas conceitos sobre competências e habilidades, descrevem as diferenciações e o aprofundamento dos referidos termos semelhantes.

\section{COMPETÊNCIAS TRANSVERSAIS NO AMBIENTE DAS ORGANIZAÇÕES}

As competências transversais ou soft skills são atitudes comportamentais inatas ou aperfeiçoadas por cada pessoa e estão relacionadas com a inteligência emocional, com as habilidades mentais de cada ser humano e determinam a capacidade de gestão e de relacionamento interpessoal, diferenciando de forma positiva um profissional dos seus colegas no ambiente de trabalho (Moura et al, 2015).

Em outros termos, cada ser humano é caracterizado através de atitudes comportamentais inatas relacionadas com a inteligência emocional com as habilidades mentais que determinam o relacionamento pessoal e interpessoal de cada ser. Na ótica de Tien et al. (2003) apresenta como características das competências transversais:

- Multifuncionalidade: são necessárias em diferentes facetas da vida, tais como família, vida social, profissional.

- Transferibilidade: não são usadas apenas na escola, na sociedade ou no mundo do trabalho, mas também na vida pessoal, no desenvolvimento da carreira, na aprendizagem ao longo da vida, dentre outros.

- Baseadas na cognição: a sua construção envolve reflexões individuais ativas e processos mentais que incluem o pensamento crítico, resolução de problemas, criatividade, inovação.

- Multidimensionalidade: são compostas por diferentes clusters de competências, tais como cognitivo, interpessoal, empresarial, preparação para o trabalho.

- Aprendizagem: são aprendidas no âmbito de um processo on-going através de diferentes contextos, tais como escola, redes sociais, contextos de trabalho.

- Abrangência: são mais abrangentes do que o conhecimento, sendo explanações e aplicações desse mesmo conhecimento. 
Ainda, para Moura et al. (2015), no seu artigo, este enfatiza a pesquisa dentre as diversas competências transversais citadas, em três delas consideradas extremamente importantes para um melhor desempenho empresarial: o trabalho em Equipe; Inteligência Emocional e Resiliência. Desse modo, o trabalho em uma organização supera expectativas trazendo um desenvolvimento enriquecedor para o colaborador e sucesso empresarial.

\section{MÉTODO}

O presente estudo que tem como objetivo compreender, por meio da literatura da área de Gestão de Pessoas a abordagem entre as competências transversais de trabalhadores em organizações de ensino superior tem enfoque qualitativo, bibliográfico e de caráter explicativo. Assim, Lakatos et al. (2017), em relação a abordagem qualitativa, explicam que o problema da pesquisa é oriundo da imersão do pesquisador no contexto do estudo. Nesse sentido, busca-se compreender o significado que os fatos atribuem aos problemas identificados pelo pesquisador. Em relação a análise dos dados, tem-se como objeto de pesquisa textos, material audiovisual, descrição e análise de temas e significado profundo dos resultados. Dessa maneira, os resultados podem ser emergentes e flexíveis, reflexivos e abertos à aceitação de outras tendências.

Em outras palavras, a pesquisa qualitativa se atém na exploração, explicação e entendimento do problema. Desse modo, a abordagem qualitativa parte do fundamento de que há uma relação eficaz entre o mundo real e o sujeito, ou seja, uma interdependência viva entre o sujeito e o objeto, um vínculo inseparável entre o mundo objetivo e a subjetividade do sujeito.

Lakatos et al. (2010) enfatizam que a pesquisa bibliográfica, ou de fontes secundárias, abrange toda bibliografia já tornada pública em relação ao tema de estudo, desde publicações avulsas, boletins, jornais, revistas, livros, pesquisas, monografias, teses, material cartográfico, até meios de comunicação oral: rádio, gravações em fita magnética e audiovisuais: filmes e televisão. Desse modo, tem por finalidade colocar o pesquisador em contato direto com tudo o que foi escrito, dito ou filmado sobre determinado assunto, inclusive conferências seguidas de debates que tenham sido transcritos por alguma forma, querem publicadas, quer gravadas. Dessa forma, a pesquisa bibliográfica propicia a análise de um tema sob novo enfoque ou abordagem, chegando a conclusões inovadoras.

Ainda este estudo classificou-se como descritivo, pois procurou-se, por meio dos dados coletados descrever a situação encontrada. Para Gerhardt e Silveira (2009, p. 35) “a pesquisa descritiva exige do investigador uma série de informações sobre o que deseja pesquisar. Esse tipo de estudo pretende descrever os fatos e fenômenos de determinada realidade". Assim, faz-se relevante para esta pesquisa.

Para a coleta de dados utilizou-se da plataforma intitulada Scielo, conhecida como Biblioteca Eletrônica Científica Online (do inglês Scientific Electronic Library Online - Scielo) é uma biblioteca digital de livre acesso e modelo cooperativo de publicação digital de periódicos científicos brasileiros, 
resultado de um projeto de pesquisa da Fundação de Amparo à Pesquisa de São Paulo (FAPESP), em parceria com a Centro Latino-Americano e do Caribe de Informação em Ciências da Saúde (Bireme). Assim, o referido repositório foi escolhido por ser específico, amplo e por ter acesso a todos os artigos pesquisados conveniados com a Capes.

A seguir, consta quadro com os descritores utilizados para a realização desta pesquisa.

Quadro 1 - Descritores da pesquisa.

\begin{tabular}{|l|}
\hline Descritores: \\
\hline Gestão de pessoas x Competências transversais x Instituições de ensino superior \\
\hline Gestão de pessoas x Competências transversais \\
\hline Gestão de pessoas x Instituições de ensino superior \\
\hline Competências transversais x Instituições de ensino superior \\
\hline
\end{tabular}

Fonte: Elaborado pelos autores

Nesta etapa de coleta de dados, utilizou-se a plataforma Scielo, na qual foram selecionados artigos, publicados nos últimos quatro anos (2017, 2018, 2019, 2020), sendo que o total de artigos buscados consistiu em um total de quatro artigos (um por ano).

No que tange a análise dos dados, estes foram analisados de forma descritiva, possibilitando assim, descrever e interpretar os achados por meio da literatura, facilitando dessa forma, a comparação da teoria existente. Ainda, os resultados foram organizados em quadros para melhor facilitar o entendimento, seguindo, dessa forma, alguns critérios avaliativos em cada artigo selecionado para este estudo.

Quadro 2 - Critérios para análise dos artigos.

\begin{tabular}{|l|}
\hline Critérios para análise dos artigos \\
\hline - Título do artigo \\
\hline Revista em que o artigo foi publicado \\
\hline Data de publicação \\
\hline - Autores \\
\hline - Área do conhecimento \\
\hline Conjunto de descritores utilizado \\
\hline - Objetivo do artigo \\
\hline - Resumo do artigo \\
\hline Fonte: Elaborado pelos autores
\end{tabular}

$\mathrm{Na}$ análise, portanto, o intuito é demostrar os dados bibliométricos do artigo, como visto, mas também, ao se abordar o resumo do artigo, a análise se concentrará em compreender como o texto do documento, se relaciona com o objetivo deste trabalho. 


\section{RESULTADOS E DISCUSSÃO}

Nesta seção, são apresentados os resultados da pesquisa, tanto em nível bibliométrico como em nível bibliográfico. Para esta seção, foram realizadas pesquisas e buscas na base de dados da Scielo, a partir dos critérios apresentados no capítulo 3 deste trabalho.

\section{APRESENTAÇÃO DOS DADOS BIBLIOMÉTRICOS DOS ARTIGOS}

No quadro abaixo, abordar-se-á os dados bibliométricos coletados em artigos, publicados nos últimos quatro anos. Assim, os resultados aqui abordados foram os seguintes:

Quadro 3 - Dados Bibliométricos.

\begin{tabular}{|c|c|c|c|c|c|}
\hline $\begin{array}{l}\text { Ano/Data } \\
\text { publicação }\end{array}$ & Título & $\begin{array}{c}\text { Impacto da } \\
\text { Revista/Qualis }\end{array}$ & Revista & Autores & $\begin{array}{c}\text { Área do } \\
\text { conhecimento }\end{array}$ \\
\hline 2017 & $\begin{array}{l}\text { Abordagem de competências, } \\
\text { desenvolvimento humano e } \\
\text { educação superior }\end{array}$ & $\begin{array}{l}\text { Internacional/Não } \\
\text { disponibilizado } \\
\text { na Plataforma } \\
\text { Sucupira }\end{array}$ & $\begin{array}{l}\text { Psicologia: Teo- } \\
\text { ria e Pesquisa }\end{array}$ & $\begin{array}{l}\text { Claisy Maria Marinho Araujo, } \\
\text { Leandro S. Almeida }\end{array}$ & Saúde \\
\hline 2018 & $\begin{array}{l}\text { Desenvolvimento de competên- } \\
\text { cias transversais na Universi- } \\
\text { dade de Múrcia: fortalezas, fra- } \\
\text { quezas e propostas de melhora }\end{array}$ & $\begin{array}{l}\text { Internacional/Não } \\
\text { disponibilizado } \\
\text { na Plataforma } \\
\text { Sucupira }\end{array}$ & $\begin{array}{l}\text { Revista Digital } \\
\text { de Pesquisa em } \\
\text { Ensino Univer- } \\
\text { sitário }\end{array}$ & $\begin{array}{l}\text { Natalia González Morga, } \\
\text { Javier Pérez Cusó, Mirian } \\
\text { Martínez Juárez }\end{array}$ & Educação \\
\hline 2019 & $\begin{array}{l}\text { O Desenvolvimento da compe- } \\
\text { tência transversal dos gestores } \\
\text { de serviço de saúde }\end{array}$ & Internacional/A2 & $\begin{array}{l}\text { Revista de Saú- } \\
\text { de Pública }\end{array}$ & $\begin{array}{l}\text { Roberto Gonzalez Duarte, } \\
\text { Irene Kazumi Miura, Namie } \\
\text { Okino Sawada, Marilia Alves, } \\
\text { Renata Petrin }\end{array}$ & Saúde \\
\hline 2020 & $\begin{array}{l}\text { O impacto das habilidades de } \\
\text { pós-graduação no trabalho: o } \\
\text { caso dos graduados da Univer- } \\
\text { sidad Veracruzana no México }\end{array}$ & $\begin{array}{l}\text { Internacional/ } \\
\text { Não disponibiliza- } \\
\text { do na Plataforma } \\
\text { Sucupira }\end{array}$ & $\begin{array}{l}\text { CPU-e. Journal } \\
\text { of Educational } \\
\text { Research }\end{array}$ & $\begin{array}{l}\text { Teresita de Jesús Méndez } \\
\text { Rebolledo, Jordi Suriñach, } \\
\text { Mario Miguel Ojeda Ramírez }\end{array}$ & Educação \\
\hline
\end{tabular}

Fonte: Elaborado pelos autores.

Os artigos pesquisados e selecionados para esta análise referenciam os anos de 2017 a 2020. Assim, as revistas os quais, esses estão vinculadas a universidades, relacionadas a área da educação e saúde. Os artigos relacionam-se a profissionais da área da educação (docentes, discentes, pesquisadores e a toda comunidade acadêmica) e também a área da saúde (psicologia).

Duas das revistas são nacionais e as outras duas internacionais. Estão disponíveis na versão impressa e na versão on-line. Os(as) autores(as) são brasileiros(as) e internacionais (mexicanos, espanhóis) e têm titulação em doutorado. Os referidos artigos apresentam palavras relacionadas ao objetivo proposto da pesquisa no título dos trabalhos e, da mesma forma, coincidem com as palavras-chave deste trabalho (Capacidades; Gestão de pessoas; Instituições; Educação), o que já foi um mecanismo para a seleção dos textos. 
De acordo com os textos pesquisados, nem todos os ramos de estudo que se dedicam ao estudo dos conceitos de competências são restritos às ciências sociais aplicadas. Dessa maneira, pode-se dizer que a ciência esta relacionada a uma sistematização de conhecimentos, um conjunto de proposições logicamente correlacionadas sobre o comportamento de certos fenômenos que se deseja estudar. Além disso, apesar de várias abordagens diferentes com relação ao conceito de competência, grande parte dos autores concordam com a ideia de que competência se refere à aprendizagem e ao desenvolvimento adquiridos na realização adequada e observável de um determinado tipo de atividade ou tarefa.

\section{APRESENTAÇÃO E ANÁLISE DOS ASPECTOS BIBLIOGRÁFICOS DOS ARTIGOS}

Nesta seção tem-se exposto a análise referente aos artigos encontrados nas bases de dados que envolvem a temática aborda neste estudo. Assim, utilizou-se para a construção do mesmo um conjunto de descritores que possibilitaram uma percepção de como os autores trataram as competências transversais e as instituições de ensino superior em suas respectivas pesquisas, os quais foram publicados nos anos de 2017, 2018, 2019 e 2020. Para tanto, utilizou-se os seguintes descritores:

- Competências transversais x Instituições de ensino superior

- Competências transversais x Instituições de ensino superior

- Gestão de pessoas x Competências transversais

- Gestão de pessoas x Instituições de ensino superior

- Gestão de pessoas x Competências transversais x Instituições de ensino superior

- Gestão de pessoas x Competências transversais x Instituições de ensino superior

Assim, de antemão, ao aplicar os descritores nas bases de dados, percebeu-se que esta temática ainda e pouco explorada, visto que, pelo número mínimo de estudos encontrados e a forma como os autores abordaram o tema, ainda há muito que explorar o assunto dentro do contexto abordado, pois este é palco para a construção destas competências e requer diferentes tratamentos. Na concepção de Silva e Teixeira (2012) as IES têm promovido mudanças na grade curricular com o objetivo de desenvolver tais competências aos alunos, facilitando sua inserção e ascensão profissional, pois a demanda por profissionais com perfil adequado à realidade do ambiente organizacional é muito valorizada pelos empregadores, e as IES, principalmente tecnológico, cujo objetivo é a formação profissional e possui um papel fundamental na aquisição e no desenvolvimento das competências técnicas e transversais. Tal ação, segundo os autores, propicia ao graduando a possibilidade de tornar-se empregável, ou seja, permitindo ao aluno adquirir e desenvolver habilidades e competências que lhes possibilite uma melhor inserção no mercado de trabalho. 
Por meio do Quadro 4, tem-se os aspectos abordados nos estudos selecionados por meio da aplicabilidade dos descritores, os quais, foram utilizados como base para uma abrangência macro do tema competências transversais e IES, fazendo-se necessário abarcar, também, temáticas como gestão de pessoas, visto que, notou-se um direcionamento para os recursos que envolvem os indivíduos nestas instituições.

Quadro 4 - Aspectos bibliográficos.

\begin{tabular}{|c|c|c|c|}
\hline $\begin{array}{c}\text { Ano/Data de } \\
\text { publicação }\end{array}$ & $\begin{array}{c}\text { Conjunto de descritores } \\
\text { utilizado }\end{array}$ & Objetivo do artigo & Resumo do artigo \\
\hline 2017 & $\begin{array}{l}\text { Competências } \\
\text { transversais x } \\
\text { Instituições de } \\
\text { ensino superior }\end{array}$ & $\begin{array}{l}\text { Apresentar uma catego- } \\
\text { rização de competências } \\
\text { transversais e possibilida- } \\
\text { des para a sua avaliação. }\end{array}$ & $\begin{array}{l}\text { Tendo como fundamento a psicologia do desenvolvimento } \\
\text { humano, apresenta-se, neste artigo, uma ampliação conceitual } \\
\text { à compreensão de competência. Esse é um termo polissêmico, } \\
\text { com multiplicidade de concepções epistemológicas, éticas e } \\
\text { ideológicas que imprimem complexidade aos processos formati- } \\
\text { vos, especialmente em relação à formação pessoal e profissional } \\
\text { na educação superior. Defende-se a noção de competência an- } \\
\text { corada na mobilização intencional de diversos recursos próprios } \\
\text { ao desenvolvimento humano: processos psicológicos, compor- } \\
\text { tamentos, conhecimentos, afetos, crenças, habilidades, escolhas } \\
\text { éticas e estéticas, que devem ser mobilizados pelo sujeito. A } \\
\text { reflexão pode fundamentar uma atuação crítica de psicólogos e } \\
\text { educadores para a mediação do desenvolvimento de competên- } \\
\text { cias dos atores do ensino superior. }\end{array}$ \\
\hline 2018 & $\begin{array}{l}\text { Competências } \\
\text { transversais x } \\
\text { Instituições de } \\
\text { ensino superior } \\
\text { Gestão de pessoas x } \\
\text { Competências transver- } \\
\text { sais } \\
\text { Gestão de pessoas x } \\
\text { Instituições de ensino } \\
\text { superior }\end{array}$ & $\begin{array}{l}\text { Conhecer o desenvolvi- } \\
\text { mento de competências } \\
\text { transversais nas salas } \\
\text { de aula da Universidade } \\
\text { de Murcia a partir da } \\
\text { percepção dos alunos do } \\
\text { último ano da Licencia- } \\
\text { tura. } \\
\text { Identificar os pontos } \\
\text { fortes e fracos da for- } \\
\text { mação em competências } \\
\text { transversais por meio da } \\
\text { visão dos alunos. } \\
\text { Analisar as propostas de } \\
\text { melhoria estabelecidas } \\
\text { pelos alunos na forma- } \\
\text { ção em competências } \\
\text { transversais. }\end{array}$ & $\begin{array}{l}\text { O desenvolvimento de competências transversais no ensino } \\
\text { superior reveste-se de especial interesse pela sua vinculação ao } \\
\text { contexto sócio-laboral. A inclusão dessas competências no cur- } \\
\text { rículo universitário é irregular e complexa. Trabalho em equipe, } \\
\text { interação social, compromisso ético-social e controle emocional } \\
\text { são, entre outras, competências-chave dos profissionais de nosso } \\
\text { tempo. Pretende-se, a partir deste trabalho, conhecer o grau de } \\
\text { desenvolvimento destas quatro competências transversais e iden- } \\
\text { tificar os seus pontos fortes e fracos no seu processo formativo, } \\
\text { para, por fim, analisar as propostas de melhoria apresentadas } \\
\text { por } 1.137 \text { alunos finalistas dos cinco ramos do conhecimento. da } \\
\text { Universidade de Murcia. O questionário CECTGRA é aplicado, } \\
\text { cujas respostas são analisadas a partir de uma abordagem mista } \\
\text { que alterna a utilização dos programas SPSS v23 e ATLAS.TI } 7 . \\
\text { Os resultados indicam a necessidade de melhorar o desenvolvi- } \\
\text { mento de competências; o trabalho em equipe é o mais desenvol- } \\
\text { vido, estando no polo oposto, o controle emocional, encontrando } \\
\text { diferenças significativas entre os ramos do conhecimento. Os } \\
\text { pontos fortes identificados são agrupados em relação ao próprio } \\
\text { aluno, o ambiente e a estrutura, e as fragilidades e propostas de } \\
\text { melhoria em torno da instituição, do centro e da sala de aula. }\end{array}$ \\
\hline
\end{tabular}




\begin{tabular}{|c|c|c|c|}
\hline 2019 & $\begin{array}{l}\text { Gestão de pessoas } \mathrm{x} \\
\text { Competências } \\
\text { transversais } \mathrm{x} \\
\text { Instituições de } \\
\text { ensino superior }\end{array}$ & $\begin{array}{l}\text { Problematizar as ques- } \\
\text { tões da saúde sob diferen- } \\
\text { tes perspectivas teóricas. } \\
\text { Analisar as questões da } \\
\text { área da saúde a partir } \\
\text { de diversos prismas não } \\
\text { implica necessariamente } \\
\text { no desenvolvimento de } \\
\text { competências transver- } \\
\text { sais. O desenvolvimento } \\
\text { e a aplicação dessas com- } \\
\text { petências pressupõem ir } \\
\text { além da integração entre } \\
\text { conteúdos curriculares e } \\
\text { entre teoria e prática. }\end{array}$ & $\begin{array}{l}\text { Em seus projetos pedagógicos, os cursos de gestão de saúde } \\
\text { privilegiam a multidisciplinaridade, interdisciplinaridade, inte- } \\
\text { gralidade e transversalidade, cujo principal mérito é problema- } \\
\text { tizar as questões da saúde sob diferentes perspectivas teóricas. } \\
\text { Analisar as questões da área da saúde a partir de diversos } \\
\text { prismas não implica necessariamente o desenvolvimento de } \\
\text { competências transversais. O desenvolvimento e a aplicação } \\
\text { dessas competências pressupõem ir além da integração entre } \\
\text { conteúdos curriculares e entre teoria e prática. Dependem de } \\
\text { como os conhecimentos serão articulados às mudanças nos } \\
\text { níveis organizacional, setorial e institucional e da coevolu- } \\
\text { ção entre essas competências e essas mudanças. Entende-se } \\
\text { que a atuação do gestor de serviços de saúde é efetivamente } \\
\text { transversal quando: (i) atua nas fronteiras organizacionais, } \\
\text { fomentando a interação entre as organizações e outros atores } \\
\text { do sistema; (ii) provê (e recebe) feedbacks para esses (desses) } \\
\text { atores; e (iii) esses feedbacks auxiliam os tomadores de decisão } \\
\text { a empreender mudanças organizacionais, de modo a responder } \\
\text { ao ambiente e a moldá-lo. }\end{array}$ \\
\hline 2020 & $\begin{array}{l}\text { Gestão de pessoas } \mathrm{x} \\
\text { Competências } \\
\text { transversais } \mathrm{x} \\
\text { Instituições de } \\
\text { ensino superior }\end{array}$ & $\begin{array}{l}\text { O objetivo é consolidar, } \\
\text { a partir do PNPC, um } \\
\text { sistema de formação de } \\
\text { capital humano para en- } \\
\text { frentar os desafios da so- } \\
\text { ciedade do conhecimento. } \\
\text { Assim, nos últimos vinte } \\
\text { anos houve um impor- } \\
\text { tante desenvolvimento da } \\
\text { pós-graduação nacio- } \\
\text { nal, não só em termos } \\
\text { quantitativos (número de } \\
\text { programas e matrículas } \\
\text { de alunos em mestrado e } \\
\text { doutorado), mas também } \\
\text { na diversificação das } \\
\text { áreas de estudo, localiza- } \\
\text { das regionalmente. }\end{array}$ & $\begin{array}{l}\text { Apresentamos uma análise das competências genéricas que os } \\
\text { egressos declaram possuir: (1) antes de iniciar os estudos, (2) } \\
\text { as que adquiriram durante os estudos e ( } 3 \text { ) as exigidas pelo } \\
\text { desempenho no trabalho. Testes de hipóteses são realizados, } \\
\text { modelos de regressão linear e modelos logísticos multinomiais } \\
\text { são ajustados. } \\
\text { Constatou-se que as competências mais adquiridas e mais apli- } \\
\text { cadas estão relacionadas à profissionalização, ao pensamento } \\
\text { analítico, à liderança e às habilidades expositivas. Conclui-se } \\
\text { que existem semelhanças entre os níveis em que os egressos } \\
\text { alcançam as competências com a sua aplicação na área em que } \\
\text { atuam. Mostra-se que existem competências altamente especia- } \\
\text { lizadas obtidas na pós-graduação (habilidades de comunicação, } \\
\text { liderança e pesquisa). }\end{array}$ \\
\hline
\end{tabular}

Fonte: Elaborado pelos autores.

Em análise ao Quadro 4, constatou-se que o conjunto de descritores aparece nos referidos artigos no título, nas palavras-chave e no artigo todo, como é possível verificar no seguinte trecho: nessa linha de novas configurações na educação superior, torna-se fundamental elaborar alternativas teórico-metodológicas de pesquisa que consigam evidenciar a forma de melhor articular teoria e prática nesse nível de ensino e de como desenvolver competências, em especial as transversais, vinculadas às vivências dos estudantes em seus contextos acadêmicos de formação (MARINHO-ARAUJO et al. 2017).

No que diz respeito aos objetivos dos artigos, percebeu-se da mesma forma, aproximação entre os descritores selecionados, como é possível perceber no trecho: Conhecer o desenvolvimento de 
competências transversais nas salas de aula da Universidade de Murcia a partir da percepção dos alunos do último ano da Licenciatura (GONZALEZ MORGA et al. 2018).

Os resumos dos artigos, apresentam os resultados condizentes aos objetivos e que revelam adequação das propostas de pesquisa. Contudo, tanto a nível de objetivos e de resultados, verificou-se que os textos se afastaram do objetivo principal deste artigo, que consistiu em focar o desenvolvimento de habilidades e competências no contexto de trabalhadores de Universidades.

Nesse sentido, não se encontrou referência a esta proposta, nos artigos pesquisados. Sabe-se que as Universidades têm como propósito a formação de estudantes, tanto humana como profissional. E sabe-se que esse público, está no centro das atenções do trabalho realizado nessas Instituições. Contudo, uma observação se faz importante: muito do trabalho realizado nas e pelas Universidades, está relacionado a atuação de servidores e técnico - administrativos, responsáveis diretos pelo planejamento e execução de ações que impactam no processo de formação dos alunos.

Ainda, é possível perceber por meio dos artigos, principalmente nos resultados encontrados, uma necessidade de desenvolvimento das competências em relação aos discentes, mas também, tal pensamento se expande ao ambiente e estrutura que estas oferecem, conforme fica evidente no seguinte trecho: "os resultados indicam a necessidade de melhorar o desenvolvimento de competencias; o trabalho em equipe é o mais desenvolvido, estando no polo oposto, o controle emocional, encontrando diferenças significativas entre os ramos do conhecimento. Os pontos fortes identificados são agrupados em relação ao próprio aluno, o ambiente e a estrutura, e as fragilidades e propostas de melhoria em torno da instituição, do centro e da sala de aula”. Complementando o exposto nota-se uma evidencia no trecho: "Dependem de como os conhecimentos serão articulados às mudanças nos níveis organizacional, setorial e institucional e da coevolução entre essas competências e essas mudanças".

Por fim, compreende-se que os profissionais que atuam nas Instituições de Ensino, ocupam um papel estratégico e devem ser considerados como recursos formadores também, pois integram quadros de trabalho permanente tanto de planejamento como de suporte para a execução das ações educacionais. Assegurar que trabalhadores das Universidades recebam atenção formadora é requisito fundamental para que todo o trabalho das Instituições, como foco no estudante, seja realizado dentro de padrões de qualidade e inovação esperados e projetados a estes ambientes.

\section{CONSIDERAÇÕES FINAIS}

O objetivo deste trabalho consistiu compreender, por meio da literatura da área de Gestão de Pessoas a abordagem entre as competências transversais de trabalhadores em organizações de ensino superior. Assim, como resultado, selecionaram-se 4 textos, publicados em revistas de diferentes áreas (educação, saúde), as quais têm conexão com o enfoque deste trabalho de forma indireta. No que diz respeito à educação, relaciona-se com o segmento analisado: instituições de ensino superior. No que 
diz respeito à saúde, observa-se interesse na oferta de serviços de qualidade, e isso relaciona-se ao bom desempenho de trabalhadores da área.

O conjunto de descritores utilizados na busca dos textos da base Scielo, demonstraram relevância, pois encontram-se presentes no corpo textual dos artigos pesquisados, e também, em outros elementos como título e palavras-chave. Contudo, a utilização desses descritores não apresentou resultados satisfatórios no que diz respeito ao objetivo desta pesquisa.

As buscas realizadas não trouxeram textos que abordassem o contexto do trabalho e das competências transversais nas Universidades e Instituições de Ensino Superior. Dedicando-se a analisar este contexto, no processo de formação do aluno, a formação profissional, realizada em sala de aula, o que inclui diretamente o trabalho do professor.

Constou-se que, no contexto geral apresentado nos resumos, no que se refere, sobretudo, à metodologia, aos resultados e à conclusão, os textos apresentaram as competências no âmbito discente nas organizações superiores. Em suma, encontrou-se menção a estudos que trabalham a questão das competências transversais dentro do contexto das Universidades, mas voltados aos discentes, ao processo formativo dos acadêmicos, mas nenhum voltado ao contexto dos colaboradores técnico - administrativos responsáveis, em grande parte, pelo planejamento e pela execução dos trabalhos que impactam na qualidade da formação entregue aos alunos. Dessa forma, avalia-se como relevante, para uma próxima pesquisa, refinar a busca, incluindo outros descritores, como trabalho administrativo $\mathrm{x}$ técnico - administrativos $\mathrm{x}$ trabalho.

Por fim, as limitações encontradas neste estudo apresentaram-se como estruturais, ou seja, na forma com que os artigos pesquisados são confeccionados, pois dependendo das normas de apresentação e formatação, bem como os periódicos aos quais estão acoplados, dificultou em partes suas análises, requerendo dos pesquisadores um interpretativismo maior.

\section{REFERÊNCIAS}

DUARTE, R. G. et al . O desenvolvimento da competência transversal dos gestores de serviços de saúde. Revista de Saúde Pública, v. 53, n. 74, 2019.

GARCIA, E. S. M.; MANTOVANI, F. A. Mapeamento das Competências Transversais: autopercepção dos alunos de Gestão Empresarial em uma Instituição de Ensino Superior Tecnológica. Plures Humanidades, v. 18, p. 177-195, 2017.

GERHARDT, T. E.; SILVEIRA, D. T. Métodos de pesquisa. $1^{\mathrm{a}}$ ed. Editora UFRGS. Porto Alegre, 2009. 
GONZALEZ MORGA, N. et al. Desarrollo de Competencias Transversales en la Universidad de Murcia: Fortalezas, Debilidades y Propuestas de Mejora. Revista Digital de Investigación en Docencia Universitaria, v. 12, n. 2, p. 88-113, 2018.

LAKATOS, E. M.; MARCONI, M. A. Fundamentos da metodologia científica. 7. ed. São Paulo: Atlas, 2010.

LAKATOS, E. M.; MARCONI, M. A. Metodologia científica. 7. ed. São Paulo: Atlas, 2017.

MARINHO-ARAUJO, C. M.; ALMEIDA, L. S. Abordagem de competências, desenvolvimento humano e educação superior. Psicologia: Teoria e Pesquisa, v. 32, n. 1, 2016.

MARTINS, J. C. C. Soft Skills: Conheça as ferramentas para você adquirir, consolidar e compartilhar conhecimentos. Rio de Janeiro: Brasport, 2017.

MOSCOVICI, F. A organização interpessoal. Treinamento em grupos. Rio de Janeiro: José Olympio, 2007.

MOURA, D.; ZOTES, L. Competências transversais e desempenho empresarial: uma análise conceitual comparativa. Revista Eletrônica Sistemas \& Gestão, v. 10, p. 254-269, 2015.

SILVA, B. M. B.; TEIXEIRA, M. A. Autopercepção de competências transversais de trabalho em universitários: construção de um instrumento. Estudos de Psicologia, v. 17, p. 199-206, 2012.

SWIATKIEWICZ, O. Competências transversais, técnicas ou morais: um estudo exploratório sobre as competências dos trabalhadores que as organizações em Portugal mais valorizam. Cadernos EBAPE, v. 12, n. 3, p. $663-687,2014$. 